\title{
Quantification of Water Impurity in an Atomic Layer Deposition Reactor Using Group Contribution Method
}

ISSN: 2576-8840

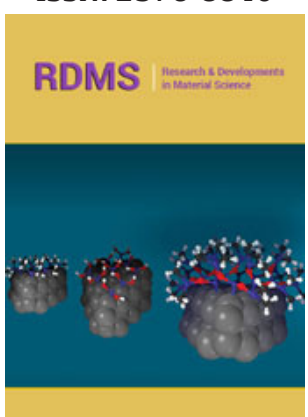

*Corresponding author: Christos G Takoudis, Department of Chemical Engineering and Bioengineering, University of Illinois at Chicago, USA Urmila M Diwekar, Department of Bioengineering, University of Illinois at Chicago, USA

Submission: 侮June 18, 2021

Published: 㘹June 23, 2021

Volume 15 - Issue 3

How to cite this article: Mina Shahmohammadi, Rajib Mukherjee, Christos G Takoudis, Urmila M Diwekar Quantification of Water Impurity in an Atomic Layer Deposition Reactor Using Group Contribution Method. Res Dev Material Sci. 15(3). RDMS.000864. 2021 DOI: $10.31031 /$ RDMS.2021.15.000864

Copyright@ Christos G Takoudis and Urmila M Diwekar. This article is distributed under the terms of the Creative Commons Attribution 4.0 International License, which permits unrestricted use and redistribution provided that the original author and source are credited.

\author{
Mina Shahmohammadi ${ }^{1}$, Rajib Mukherjee ${ }^{2,3}$, Christos G Takoudis ${ }^{1,4 *}$ and \\ Urmila M Diwekar ${ }^{2,4 *}$ \\ ${ }^{1}$ Department of Chemical Engineering, University of Illinois at Chicago, USA \\ ${ }^{2}$ Vishwamitra Research Institute, USA \\ ${ }^{3}$ Department of Chemical Engineering, University of Texas Permian Basin, USA \\ ${ }^{4}$ Department of Bioengineering, University of Illinois at Chicago, USA
}

\begin{abstract}
Atomic Layer Deposition (ALD) is a vapor phase process to deposit thin films using precursors and co-reactants on a variety of substrates. The ALD system, the data of which is used here, had aimed to deposit TiO2 thin films on polymethyl methacrylate (PMMA) and silicon reference substrates using tetrakis(dimethylamido)titanium and ozone. Absorbed water molecules in PMMA were released into the reactor during deposition, acted as a co-reactant, and affected the growth rate on the silicon reference substrate. The objective of this work is to theoretically calculate the amount of water impurities in the ALD reactor during several number of cycles. A group contribution method based on Adsorbate Solid Solution Theory (ASST) is employed to theoretically estimate the number of moles of water in the abovementioned ALD reactor.
\end{abstract}

Keywords: Atomic Layer Deposition (ALD); Thin films; Nanostructured materials; Titanium dioxide; Group contribution method

\section{Introduction}

Ultra-thin films of various nanostructured materials are producible with Atomic Layer Deposition (ALD) for a wide range of applications from semiconductors to biomedical areas. ALD is performed based on the chemisorption of a precursor material on the active sites of the substrate surface, which later reacts with the oxidizer/co-reactant. The thickness of the films produced by ALD is precisely controlled through cyclic, sequential, and self-limiting reactions [1]. Previous researchers have focused on describing different aspects of ALD through experiments and theory [2,3]. For instance, the ALD growth rate was modeled and related to the size of the reactant, chemisorption process, and process conditions such as temperature or precursor pulse time [3-5]. Adsorbate Solid Solution Theory (ASST) can be applied to incorporate the effects of functional groups through a group Contribution Method (GCM) and predict adsorption of a compound [6-9].

Our previous study employed GCM based on ASST to predict the thermodynamic properties, such as the binary interaction parameters between the functional groups of ALD precursors and the substrates. The goal was to use those properties for the optimal design of novel precursor materials for ALD with enhanced growth rates and optimal ALD temperature. It was described in detail how to link the experimental data obtained from an ALD system to the GCM model and match the growth rate versus precursor pulse time [3] to find the interaction parameters for groups present in the molecules of precursor and substrate. In another study, we experimentally examined the growth and characteristics of titanium 
dioxide $\left(\mathrm{TiO}_{2}\right)$ ALD on the surface of polymethyl methacrylate (PMMA) and silicon reference. It was observed that during the initial cycles, the growth rate on the silicon reference, which was in the same reactor with PMMA, was higher than stand-alone silicon. We conjectured that some amounts of water molecules, trapped in PMMA, were released into the reactor during the deposition and increased the growth rate on the silicon reference surface. Beyond a specific number of cycles, the growth rate on both silicon reference and stand-alone silicon were the same. It was conjectured that after the formation of a relatively thick film on the PMMA surface, the water molecules were either depleted or trapped under the film, and their effect was diminished [10]. To support this assumption, we decided to calculate the precise amount of water molecules and theoretically support the hypothesis of water existence inside the ALD reactor. With this motivation in mind, we used the GCM model, reported earlier, to link the $\mathrm{TiO}_{2}$ film thickness over several cycles to the number of moles of water in each cycle. However, our previous study did not involve water so interactions between some of the groups like $\mathrm{SiOH}$ and $\mathrm{Ti}$ was not available. To calculate these group interactions, we used available data from other experiments, where $\mathrm{SiOH}$ and zirconium ( $\mathrm{Zr}$ ) is used. This way, we would be able to calculate the number of moles of water inside the reactor for each ALD cycle and present the reducing trend of water amount with increasing number of the ALD cycles.

\section{Methods}

Table 1: Calculated binary interaction parameters between $\mathrm{Ti}, \mathrm{Si}$, and $\mathrm{SiOH}$.

\begin{tabular}{|c|c|c|c|}
\hline Groups & Ti & Si & SiOH \\
\hline $\mathrm{Ti}$ & 0 & $-178.6^{*}$ & -59.511 \\
\hline $\mathrm{Si}$ & $6428.9^{*}$ & 0 & N/A \\
\hline $\mathrm{SiOH}$ & -8388.7 & N/A & 0 \\
\hline
\end{tabular}

Table Abbreviations: Ti (Titanium), Si (Silicon), $\mathrm{SiOH}$ (Silicon hydroxide)

*Obtained from [3].

The basic model for the use of ASST in ALD is developed and described in our previous work [3]. The GCM model is used to calculate the number of moles of water in the ALD reactor. Some changes and updates are adopted here: The water is assumed to form hydroxide on the silicon surface and increase the active sites for the reaction, and that is how the growth rate is increased. Thus, the model is updated to contain the combination of silicon (Si) and silicon hydroxide $(\mathrm{SiOH})$ as the substrate for ALD. The growth rate versus the number of cycles is modeled here (instead of growth rate versus precursor pulse times) [10]. The required ALD conditions and experimental data points are obtained from our previous study (Figure 2 in the reference) [10]. Some interaction parameters were already calculated, i.e., the binary interaction parameters between $\mathrm{Si}, \mathrm{Ti}, \mathrm{N}$, and $\mathrm{CH}_{3}$ groups (Table 1 in the reference) [3]. The rest were estimated using the interaction parameters in another system as follows: The binary interaction parameters between $\mathrm{Zr}, \mathrm{Si}$, and $\mathrm{SiOH}$ was found in another ALD system (unpublished data) in the same way described before [3], where $\mathrm{ZrO}_{2}$ was deposited on silicon. We used those values along with the parameters between $\mathrm{Ti}$ and $\mathrm{Si}$ to find the ratio between $\mathrm{Ti}$-Si and $\mathrm{Zr}$-Si binary interaction parameters. Using that ratio, we estimated the binary interaction parameters between $\mathrm{Ti}$ and $\mathrm{SiOH}$, as shown in Table 1.

\section{Results and Discussion}

Figure 1 compares the experimental and calculated moles of adsorbed titanium in each ALD cycle. The experimental moles are found from the thickness of $\mathrm{TiO}_{2}$ film deposited in the previously reported study [10]. In the given ALD condition [3], the water molecules act as co-reactant of the reaction throughout the initial cycles. This is described as cyclic-chemical vapor deposition [11], where the growth rate on silicon is higher than stand-alone silicon in similar ALD conditions. The $\mathrm{TiO}_{2}$ film thickness is calculated with GCM with three different conditions: It is assumed that

1. No water is in the reactor, and the substrate is pure silicon (red squares in Figure 1);

2. Some amounts of water exist in the reactor, and the substrate is the combination of $\mathrm{Si}$ and $\mathrm{SiOH}$ (blue circles in Figure 1).

\section{Only silicon (black diamonds in Figure 1).}

When no water is present, the theoretically predicted thickness and the number of titanium moles are lower than the actual amount. However, adding $\mathrm{OH}$ groups to the substrate would increase the predicted thickness and titanium moles.

Table 2: Moles of $\mathrm{SiOH}$, water, and titanium in the presence of water in each number of cycles.

\begin{tabular}{|c|c|c|c|c|}
\hline ALD Cycle & SiOH (Moles) & Water (Moles) & Calculated Titanium (Moles) & Experimental Titanium (Moles) \\
\hline 50 & $1.0 \mathrm{E}-12$ & $5.00 \mathrm{E}-13$ & $9.98 \mathrm{E}-08$ & $1.05 \mathrm{E}-07$ \\
\hline 100 & $4.1 \mathrm{E}-13$ & $2.05 \mathrm{E}-13$ & $1.95 \mathrm{E}-07$ & $1.94 \mathrm{E}-07$ \\
\hline 150 & $1.5 \mathrm{E}-13$ & $7.50 \mathrm{E}-14$ & $2.61 \mathrm{E}-07$ & $2.61 \mathrm{E}-07$ \\
\hline 200 & $5.8 \mathrm{E}-14$ & $2.90 \mathrm{E}-14$ & $3.01 \mathrm{E}-07$ & $2.90 \mathrm{E}-07$ \\
\hline 250 & $2.7 \mathrm{E}-14$ & $1.35 \mathrm{E}-14$ & $3.39 \mathrm{E}-07$ & $3.42 \mathrm{E}-07$ \\
\hline 350 & $5.0 \mathrm{E}-15$ & $2.50 \mathrm{E}-15$ & $4.02 \mathrm{E}-07$ & 3.96 E-07 \\
\hline
\end{tabular}

Table Abbreviations: ALD (Atomic Layer Deposition), SiOH (Silicon hydroxide)

Table 2 presents the dataset for each cycle number of ALD. The number of moles of $\mathrm{SiOH}$ is calculated by fitting the calculated moles of titanium with experimental ones. The amount of water is based on the moles of $\mathrm{SiOH}$. It is worth mentioning that the moles of $\mathrm{SiOH}$ 
and, therefore, the number of moles of titanium is decreasing with increasing the number of cycles. From the previous study [10], the growth rate on silicon reference is initially higher than the standalone silicon. In contrast, at higher cycle numbers, the growth rates match within two types of silicon substrates. It is reported that the water vapor releasing from PMMA is either depleted or trapped under the continuous film [10]. Similarly, here, it is observed that the number of moles of $\mathrm{SiOH}$ and titanium are higher at initial cycles and decrease by increasing the number of cycles.

Figure 2 displays the calculated moles of water versus the number of ALD cycles. A decreasing trend is observed when the number of cycles increases until it reaches a plateau at $\sim 0$. This is in agreement with previous work, where beyond $\sim 250$ cycles, the effect of water was diminished, and the growth rate on silicon reference was similar to the stand-alone silicon $(\sim 0.4 \AA /$ cycles $)$ (Figure $1 \& 2$ in the reference) [10].

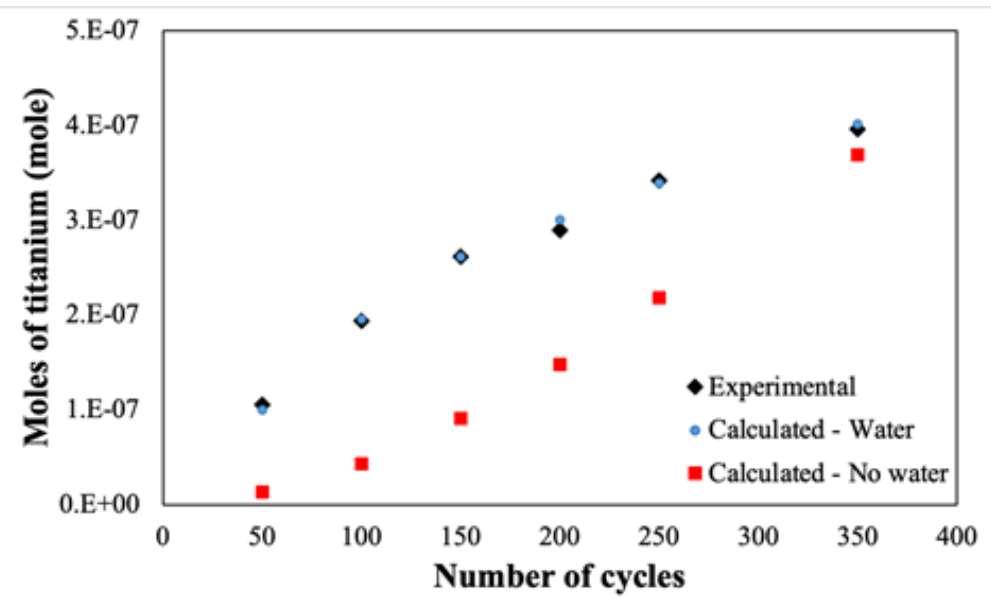

Figure 1: Comparison of experimental (diamonds) and calculated (dots in presence of water and squares in no water conditions) number of moles of titanium versus number of ALD cycles. The experimental points are found based on Figure 2 of the reference [10].

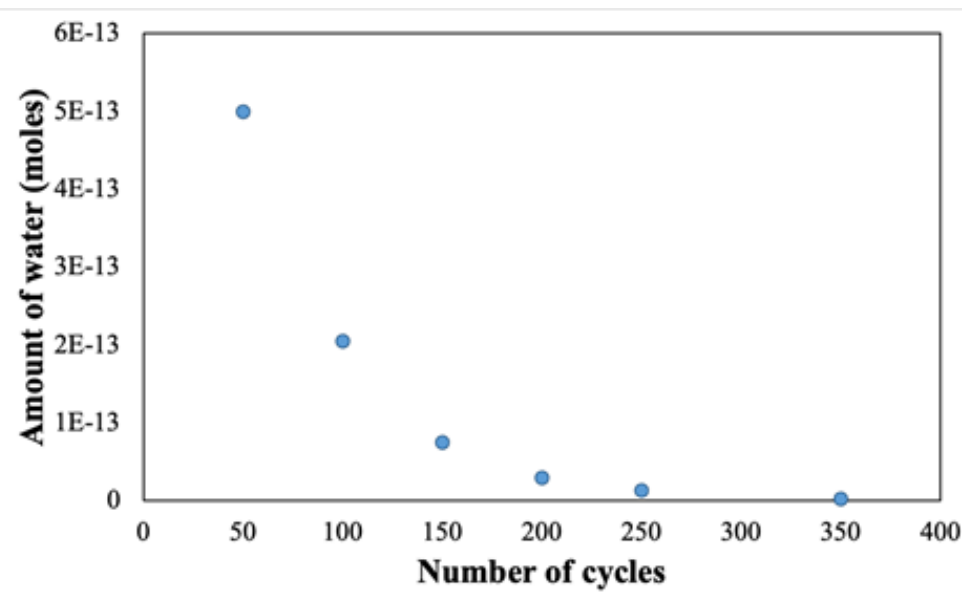

Figure 2: The number of moles of water versus number of ALD cycles.

Previous studies on ALD on organic substrates never reported the similar effect of water molecules inside the reactor. Since PMMA is a porous substrate with large free volumes [12], it is plausible to absorb water from the environment. Moreover, the pre-deposition cleaning process of PMMA involves soaking the polymer in sodium hydroxide solution and DI water for around an hour [13]. This would provide a sufficient amount of time for water absorption inside the chains of PMMA. When the substrates are in the reactor, they are heated to $120^{\circ} \mathrm{C}$, which prepares appropriate conditions for water evaporation. During the initial ALD cycles, water vapor, a common co-reactant for the precursor Tetrakis (dimethylamido) titanium (TDMAT), is released in the reactor gradually and affects the deposition.

\section{Conclusion}

An ASST-based GCM model was employed to calculate the number of moles of water molecules present in an ALD reactor reported earlier. The water vapors released from PMMA substrate during the deposition had a significant effect on the growth rate of $\mathrm{TiO}_{2}$ nanofilms on the silicon reference surface in the same 
reactor. However, the amount of water vapor was unknown. Here, the precise moles of water vapor, acting as the second co-reactant of the ALD, were calculated through a theoretical model. The decreasing trend of water moles with increasing the number of ALD cycles was predicted, in good agreement with previously reported experimental data.

\section{Acknowledgment}

The project was partially funded by the National Science Foundation (DMR-NSF-1309114).

\section{References}

1. George SM (2010) Atomic layer deposition: An overview. Chem Rev 110(1): 111-131.

2. Oviroh PO, Akbarzadeh R, Pan D, Coetzee AM, Jen T (2019) New development of atomic layer deposition: processes, methods and applications. Sci Technol Adv Mater 20(1): 465-496.

3. Shahmohammadi M, Mukherjee R, Takoudis CG, Diwekar UM (2021) Optimal design of novel precursor materials for the atomic layer deposition using computer-aided molecular design. Chem Eng Sci 234: 116416.

4. Puurunen RL (2003) Growth per cycle in atomic layer deposition: A theoretical model. Chem Vap Depos 9(5): 249-257.

5. Elliott SD (2005) Predictive process design: A theoretical model of atomic layer deposition. Comput Mater Sci 33(1-3): 20-25.

6. Berti C, Ulbig P, Burdorf A, Seippel J, Schulz S (1999) Correlation and prediction of liquid-phase adsorption on zeolites using group contributions based on adsorbate-solid solution theory. Langmuir 15(18): 6035-6042.

7. Benavides PT, Diwekar U (2014) Optimal design of adsorbents for NORM removal from produced water in natural gas fracking. Part 1: Group contribution method for adsorption. Chem Eng Sci 137: 964-976.

8. Mukherjee R, Gebreslassie B, Diwekar UM (2017) Design of novel polymeric adsorbents for metal ion removal from water using computeraided molecular design. Clean Technologies and Environmental Policy 19(2): 483-499.

9. Doshi RK, Mukherjee R, Diwekar UM (2018) Application of adsorbate solid solution theory to design novel adsorbents for arsenic removal using CAMD. ACS Sustainable Chemistry \& Engineering 6(2): 2603-2611.

10. Shahmohammadi M, Pensa E, Bhatia H, Yang B, Jursich G, et al. (2020) Enhancing the surface properties and functionalization of polymethyl methacrylate with atomic layer-deposited titanium (IV) oxide. J Mater Sci 55: 17151-17169.

11. Song X, Takoudis CG (2007) Cyclic chemical-vapor-deposited $\mathrm{TiO}_{2} / \mathrm{Al}_{2} \mathrm{O}_{3}$ film using trimethyl aluminum, tetrakis(diethylamino)titanium, and $\mathrm{O}_{2}$. J Electrochem Soc 154(8): 177-182.

12. Wilson CA, Grubbs RK, George SM (2005) Nucleation and growth during $\mathrm{Al}_{2} \mathrm{O}_{3}$ atomic layer deposition on polymers. Chem Mater 17(23): 56255634 .

13. Kääriäinen TO, Cameron DC, Tanttari M (2009) Adhesion of Ti and TiC coatings on PMMA subject to plasma treatment: Effect of intermediate layers of $\mathrm{Al}_{2} \mathrm{O}_{3}$ and $\mathrm{TiO}_{2}$ deposited by atomic layer deposition. Plasma Process Polym 6(10): 631-641.

For possible submissions Click below: 